\title{
Characterization and optimization of EPS- producing and diesel oil-degrading Ochrobactrum anthropi MP3 isolated from refinery wastewater
}

\author{
Sugumar Ramasamy, Prabhakaran Mathiyalagan and Preethy Chandran* \\ Centre for Nanotechnology and Advanced Biomaterials, School of Chemical and Biotechnology, SASTRA University, \\ Thanjavur-613 401, Tamil Nadu, India \\ (C) China University of Petroleum (Beijing) and Springer-Verlag Berlin Heidelberg 2014
}

\begin{abstract}
Petroleum refinery wastewater (PRW) containing hydrocarbon is highly toxic to the environment and the surrounding ecosystem. Proper treatment of the PRW effluent is necessary to remove the pollutants before discharge. Bioremediation is considered to be a promising approach as it is ecofriendly and efficient. The exopolysaccharide (EPS) produced by the $O$. anthropi acts as a bioemulsifier and showed the highest emulsification activity of $60 \%$ on diesel. An EPS yield of about $0.42 \mathrm{~g} / \mathrm{L}$ was obtained under optimized conditions. The carbohydrate and protein content of the EPS was found to be $71.1 \%$ and $19.7 \%$ respectively, showing the glycoprotein nature. The structural properties of EPS were analyzed by FT-IR and ${ }^{1} \mathrm{H}$ NMR. The batch degradation of oil in PRW by $O$. anthropi was studied gravimetrically, and showed about 53\% degradation in 7 days, indicating the strong ability of the isolated strain to degrade the hydrocarbons in PRW.
\end{abstract}

Key words: Hydrocarbons, Ochrobactrum anthropi MP3, EPS, bioemulsifier, degradation

\section{Introduction}

Petroleum based products are major sources of energy for industry and daily life. Leaks and accidental spills often occur during the exploration, production, refining, transport and storage of petroleum and petroleum products. The amount of natural crude oil seepage is estimated to be 600,000 metric tons per year with a range of uncertainty of 200,000 metric tons per year (Kvenvolden and Cooper, 2003). Release of hydrocarbons into the environment whether accidental or due to human activities is a main cause of water and soil pollution (Holliger et al, 1997). Soil contamination with hydrocarbons causes extensive damage of local systems since accumulation of pollutants in animals and plant tissue may cause death or mutations (Alvarez and Vogel, 1991).

Existing physical and chemical treatment methods such as electrocoagulation, electrochemical oxidation, dissolved air floatation, adsorption, skimmers and the utilization of chemical surfactants are generally expensive and of limited application. They often ended in the formation of byproducts that are as harmful as the original pollutants. Thus biological methods are preferred due to their simple, cheap and environmental friendly operations (Goris et al, 2004). Surfactants possess both hydrophilic and hydrophobic structural moieties, which in turn impart many unusual

*Corresponding author. email: preethychandran@scbt.sastra.edu Received October 22, 2013 properties, including the ability to lower the surface tension. Surface-active compounds produced by microorganisms are classified into two main types, those that reduce surface tension at the air-water interface (biosurfactants), and those that reduce the interfacial tension between immiscible liquids, or at the solid-liquid interface (bioemulsifiers). Biosurfactants usually exhibit emulsifying capacity but bioemulsifiers do not necessarily reduce the surface tension (Batista et al, 2010). The commercial importance of surfactants is evidenced from the increasing trends in their production and the number of industrial applications (Luna et al, 2011). Bioremediation technology utilizes the metabolic potential of microorganisms to clean contaminated environments. It is the metabolic ability of the microorganisms to mineralize or transform organic contaminants into less harmful substances which can be integrated into natural biogeochemical cycles. Bioremediation is an used to accelerate naturally occurring degradation by optimizing the limiting conditions. It is non-destructive and cost-effective technology (Margesin and Sohinner, 2001). Recent studies have revealed a huge diversity of microorganisms (Bacteria, fungi and Archaea) which are involved in degradation of hydrocarbons. Bacteria are the most important and abundant ones in such ecological niches. This includes species of the genera Pseudomonas, Bacillus, Alcaligenes, Mycobacterium, Arthrobacter, Xanthomonas, Alcanivorax, Acinetobacter, Micrococcus, Corynebacteria, Nocardia and Rhodococcus, which are generally known as hydrocarbonoclastic microorganisms. One of the most 
important characteristics of hydrocarbon-degrading bacteria is the ability of emulsifying hydrocarbons in solution by producing surface-active agents such as biosurfactants.

Ochrobactrum anthropi isolated from contaminated soil showed effective degradation of various polycyclic aromatic hydrocarbons (PAHs) such as phenanthrene and as well other compounds including hexane, heptane, hexadecane and pesticides (Mariano et al, 2008; Ghosal et al, 2010; Yang et al, 2013). Amphiphilic exopolysaccharide (EPS) can effectively increase solubilization of aromatic hydrocarbons and enhance degradation. Generally EPS may contain high- and lowmolecular weight proteins, non-carbohydrate constituents (such as acetate, pyruvate, succinate, and phosphate). Aminosugar, as in glucosoamine, and uronic acids were also found in EPS of some cyanobacteria (Banat et al, 2000). The EPS production by microorganisms may vary in their composition, and chemical and physical properties. Few are neutral macromolecules, but the majority is polyanionic due to the presence of either uronic acids (D-glucuronic acid being the commonest, although D-galacturonic and D-mannuronic acids are also found) or ketal-linked pyruvate. Inorganic residues, such as phosphate or rarely sulphate contribute to the polyanionic state (Sutherland, 1990). A very few EPS may even be polycationic, as exemplified by the adhesive polymer obtained from Staphylococcus epidermidis strains associated with biofilms (Mack et al, 1996 ).

In the present study, Ochrobactrum anthropi MP3 isolated from petroleum refinery waste water was subjected to exopolysaccharide analysis and petroleum hydrocarbon degradation.

\section{Materials and methods}

\subsection{Collection of petroleum refinery wastewater (PRW)}

The waste water was collected from the refinery outlet of Chennai Petroleum Corporation limited (CPCL) in North Chennai, Tamilnadu, India. The collected water was acidified and stored in a refrigerator before processing.

\subsection{Isolation of microorganism through enrichment process of PRW}

The microorganism was isolated from PRW by a modified enrichment process (Dasgupta et al, 2013). Some PRW (before acidification) was added to a nutrient broth (NB, bacterial culture broth) and incubated in a shaker. Then the culture was transferred to a fresh nutrient broth (Peptone, $5 \mathrm{~g} / \mathrm{L}$; Beef extract, $1.5 \mathrm{~g} / \mathrm{L}$; Yeast extract, $1.5 \mathrm{~g} / \mathrm{L}$ and sodium chloride, $5 \mathrm{~g} / \mathrm{L}$ ) containing $1 \%(\mathrm{v} / \mathrm{v})$ diesel (as hydrocarbon source) and kept in the shaker for 1 week. The culture was then transferred to a fresh nutrient broth containing $2 \%(\mathrm{v} / \mathrm{v})$ diesel and kept in the shaker for 1 week. Likewise 5 cycles ( 5 week), up to $5 \%(\mathrm{v} / \mathrm{v})$ diesel concentration were completed. At the end of the 5th cycle the culture was plated on nutrient agar and the microorganism was isolated.

\subsection{Identification of microorganism}

Preliminary identification of the isolated strain was conducted by gram staining and biochemical tests. Conformation was done by 16 srRNA sequencing. The total genomic DNA was extracted from bacterial colonies from the nutrient agar slant, and then suspended in 0.5 $\mathrm{mL}$ of sterilized saline, after that it was centrifuged at $10,000 \mathrm{rpm}$ for $10 \mathrm{~min}$. The pellets (microbial cells settled from culture medium during centrifugation) were suspended in $0.5 \mathrm{~mL}$ of InstaGene Matrix (Bio-Rad, USA); subsequently they were incubated at $56{ }^{\circ} \mathrm{C}$ for $30 \mathrm{~min}$ and then heated $100{ }^{\circ} \mathrm{C}$ for $10 \mathrm{~min}$. The primers PC27F/1492R (27F-AGAGTTTGATCMTGGCTCAG and 1492R- TACGGYTACCTTGTTACGACTT) underwent 35 amplification cycles at $94{ }^{\circ} \mathrm{C}$ for $45 \mathrm{sec}, 55^{\circ} \mathrm{C}$ for $60 \mathrm{sec}$, and $72{ }^{\circ} \mathrm{C}$ for $60 \mathrm{sec}$ and amplified approximately $1,400 \mathrm{bp}$. Then the products were purified by using Montage PCR Clean up kit (Millipore). The purified PCR products were sequenced by using 2 primers (518F-CCAGCAGCCGCGGTAATACG and 800R-TACCAGGGTATCTAATCC) following instructions in Big Dye terminator cycle sequencing kit (Applied Biosystems, USA). Sequencing products were analyzed on an Applied Biosystems model 3730XL automated DNA sequencing system (Applied BioSystems, USA).

\subsection{Optimization of growth conditions}

In order to optimize the growth conditions, bacterial culture $(2 \% \mathrm{v} / \mathrm{v})$ was first grown in a conical flask containing $20 \mathrm{~mL}$ nutrient broth and $1 \%(\mathrm{v} / \mathrm{v})$ diesel at $30{ }^{\circ} \mathrm{C}$ for 24 hour and it serves as the inoculum. The bacterial growth was determined by turbidity measurement (Optical density, OD) at $600 \mathrm{~nm}$.

\subsubsection{Effect of $\mathrm{pH}$}

To study the effect of $\mathrm{pH}$ on the growth of bacteria, the $\mathrm{pH}$ of the nutrient broth was varied $(\mathrm{pH} 5,6,7,8,9)$ using $\mathrm{HCl}$ and $\mathrm{NaOH}$ and the growth was continuously monitored.

\subsubsection{Effect of carbon source and its concentration}

The effect of carbon source was investigated by growing the culture in NB supplemented with different carbonbsources; glucose, sucrose and fructose. Glucose was selected as the source which can best enhance the growth of bacteria. The concentration of the glucose was varied $(1 \%$, $2 \%, 4 \% \mathrm{w} / \mathrm{v}$ ) to investigate the influence of concentration of carbon source on the growth of bacteria.

\subsubsection{Effect of nitrogen source and its concentration}

The effect of nitrogen source was investigated by growing the culture in NB supplemented with different nitrogen sources; urea, ammonium nitrate, sodium nitrate. Sodium nitrate was selected as the nitrogen source which can best enhance the growth of the bacteria. The concentration of the sodium nitrate was varied $(0.5 \%, 1 \%, 2 \% \mathrm{w} / \mathrm{v})$ to investigate the influence of concentration of nitrogen source on the growth of bacteria.

\subsubsection{Effect of diesel concentration}

The concentration of diesel as hydrocarbon source $(1 \%$, $2 \%$, and $3 \% \mathrm{v} / \mathrm{v}$ ) was studied to determine the effect of diesel on the growth of bacteria.

\subsection{EPS emulsifier production and extraction}

The bacterial culture was grown in a conical flask 
containing $200 \mathrm{~mL}$ optimized nutrient broth at $\mathrm{pH} 7$ for 5 days in a shaker at $150 \mathrm{rpm}$. After 5 days of growth, the medium was centrifuged at $36,000 \mathrm{~g}$ for $20 \mathrm{~min}$ at $4{ }^{\circ} \mathrm{C}$ to remove the biomass. Then the supernatant was precipitated with three volumes of chilled ethanol and kept at $4{ }^{\circ} \mathrm{C}$ for overnight. The precipitated medium was centrifuged and the pellet was collected, dialyzed against distilled water for 24 hours and then lyophilized.

\subsection{Biochemical characterization}

\subsubsection{Carbohydrate content}

The carbohydrate content of the EPS was determined by the anthrone reagent method (Spiro, 1996). D-glucose was used as standard.

\subsubsection{Protein content}

The Lowry test, Lowry et al (1951), was employed to determine the protein content of the EPS using bovine serum albumin as a standard.

\subsection{Activity characterization}

\subsubsection{Emulsification activity}

Emulsification activity was performed according to Cooper and Goldenberg (1987), $3 \mathrm{~mL}$ of EPS was added to an equal volume of the substrate (petrol, diesel, kerosene) and shaken vigorously for $2 \mathrm{~min}$ and then left undisturbed for 24 hours. The ability of the EPS to form a stable emulsion (emulsification activity) was expressed as the height of the emulsion layer divided by the total height.

$$
E 24=(\text { Height of the emulsion layer/Total height }) \times 100
$$

\subsubsection{Bacterial adhesion to hydrocarbon (BATH)}

Bacterial adhesion to hydrocarbon (BATH) test was performed to assess the cell surface hydrophobicity according to Rosenberg et al (1980). Bacterial cells were harvested by centrifugation at $10,000 \mathrm{~g}$ for $10 \mathrm{~min}$ at $4{ }^{\circ} \mathrm{C}$ and washed twice with PUM buffer $\left(\mathrm{KH}_{2} \mathrm{PO}_{4}, 7.2 \mathrm{~g} / \mathrm{L} ; \mathrm{K}_{2} \mathrm{HPO}_{4}, 19.7 \mathrm{~g} /\right.$ $\mathrm{L}$; Urea, $1.8 \mathrm{~g} / \mathrm{L}$ and $\mathrm{MgSO}_{4} \cdot 7 \mathrm{H}_{2} \mathrm{O} ; 0.2 \mathrm{~g} / \mathrm{L}$ ). The cells were again suspended in PUM buffer to fit an optical density of $1.0\left(A_{0}\right)$ at $600 \mathrm{~nm}$. To $2 \mathrm{~mL}$ of cell suspension, 0.5 $\mathrm{mL}$ of diesel was added and stirred for $2 \mathrm{~min}$. The optical density of aqueous phase was measured $\left(A_{1}\right)$ after $10 \mathrm{~min}$ of equilibration. The degree of hydrophobicity was calculated as

$$
H \%=\left[1-\left(A_{0}-A_{1}\right) / A_{0}\right] \times 100
$$

\subsection{Analytical characterization}

\subsubsection{FT-IR}

A lyophilized EPS sample was ground with potassium bromide $(\mathrm{KBr})$ powder and pressed with $7,500 \mathrm{~kg}$ for $30 \mathrm{~s}$ to obtain a translucent pellet. The infrared spectra were recorded on an FT-IR system within the range of $400-4,000 \mathrm{~cm}^{-1}$ wave number. A KBr pellet was used as background.

\subsubsection{NMR}

${ }^{1} \mathrm{H}$ NMR was obtained with a 5,000 MHz Brucker Avance spectrometer. The EPS sample was dissolved in deuterated chloroform and directly analyzed with ${ }^{1} \mathrm{H}$ NMR.

\subsection{Batch degradation of oil}

To study the batch degradation of oil present in PRW by the isolated microorganisms, $2 \%(\mathrm{v} / \mathrm{v})$ of overnight inoculum was added to $50 \mathrm{~mL}$ nutrient broth and 2\% (v/v) PRW was added and kept in the shaker at $150 \mathrm{rpm}$ for 1 week. The uninoculated medium containing 2\% (v/v) PRW and nutrient broth serves as control. Oil was extracted using hexane as the solvent. Hexane extracts $(1.0 \mu \mathrm{L})$ were analyzed with a Hewlett Packard 5890 Series II gas chromatograph equipped with a flame ionization detector (FID) and a $30 \mathrm{~m}$ long HP-5 column (internal diameter, $0.25 \mathrm{~mm}$, film thickness, $0.25 \mathrm{~mm}$ ). The carrier gas was nitrogen. The injector and detector temperatures were maintained at $250{ }^{\circ} \mathrm{C}$ and 350 ${ }^{\circ} \mathrm{C}$, respectively. The column was programmed at an initial temperature of $70{ }^{\circ} \mathrm{C}$, which was held for $2 \mathrm{~min}$, then ramped at $10{ }^{\circ} \mathrm{C} / \mathrm{min}$ to $320^{\circ} \mathrm{C}$ and again held for $10 \mathrm{~min}$. The degradation of oil as a whole was expressed as the percentage of diesel degraded in relation to the amount of the remaining fractions in the appropriate abiotic control samples. The biodegradation efficiency (BE), based on the decrease in the total concentration of hydrocarbons, was calculated by using the expression described by Michaud et al (2004):

$$
B E=100-\left(\frac{A_{\mathrm{s}} \times 100}{A_{\mathrm{ac}}}\right)
$$

where $B E(\%)$ is the biodegradation efficiency; $A_{\mathrm{s}}$ is the total area of peaks in each sample; and $A_{\text {ac }}$ is the total area of peaks in the appropriate abiotic control.

\section{Gravimetric analysis of oil degradation}

For gravimetric estimation of oil degradation rate, the above 7 day culture was centrifuged to remove the cells. The supernatant was transferred to a separating funnel and $5 \mathrm{~mL}$ of $n$-hexane was added and extracted. Extraction was carried twice to ensure complete recovery of oil. The extract was treated with $0.4 \mathrm{~g}$ of anhydrous sodium sulphate to remove the moisture. The dehydrated extract was evaporated to dryness in a rotary evaporator at $40{ }^{\circ} \mathrm{C}$ under reduced pressure.

The degradation (\%) of oil was calculated as follows:

Weight of residual oil= Weight of beaker containing extracted oil - Weight of empty beaker.

Amount of oil degraded $=$ Weight of crude oil present in the blank - Weight of residual oil

$$
\text { Degradation }(\%)=\frac{\text { Amount of oil degraded }}{\text { Amount of oil present in the blank }} \times 100
$$

\section{Results and discussion}

Bioremediation is considered to be a promising approach, since it is eco-friendly and feasible. The microorganism for the treatment process was isolated from the refinery waste water through an enrichment process. The bacteria which are 
able to survive and grow under high oil concentration were isolated for study, and was found to be Ochrobactrum species (Table 1).

Table 1 Physio-biochemical tests for identification of bacterial strain

\begin{tabular}{|c|c|c|}
\hline Sample No. & Physio-biochemical tests & Results \\
\hline 1 & Gram staining & Gram negative rods \\
\hline 2 & Mobility & + \\
\hline 3 & Lipid utilization & + \\
\hline 4 & Starch hydrolysis & + \\
\hline 5 & Gelatin liquefaction & - \\
\hline 6 & Fibrinolysis & - \\
\hline 7 & Voges-Proskauer(V.P) & - \\
\hline 8 & Indole reaction & - \\
\hline 9 & Glucose utilization & + \\
\hline 10 & Sucrose utilization & + \\
\hline 11 & Fructose utilization & + \\
\hline 12 & D-sorbitol utilization & - \\
\hline 13 & Arabinose utilization & + \\
\hline 14 & Rhamnose utilization & + \\
\hline 15 & Fucose utilization & + \\
\hline 16 & Glycerol utilization & - \\
\hline 17 & Cellobiose utilization & + \\
\hline 18 & Tween-40 utilization & - \\
\hline 19 & Nitrate reduction & + \\
\hline
\end{tabular}

From the 16s rRNA sequencing, and by BLAST analysis, the isolated microorganism was found to be Ochrobactrum anthropi MP3. The gene sequence was submitted to GenBank database under the accession number KF051402.

Much of what is currently known about the genus Ochrobactrum is based on its emergence as an opportunistic human pathogen. Other information is very limited (Yuan et al, 2005) perhaps due to the fact it was only described in 1988. The genus Ochrobactrum has potential applications for bioremediation. Ochrobactrum spp. demonstrate the ability to degrade phenol (El-Sayed et al, 2003), atrazine (Laura et al, 1996), halobenzoate (Bongkeuu et al, 2000), and 4-chloro-2-methylphenol (Lechner et al, 1995), to reduce toxic hexavalent chromium (Sultan and Hasnain, 2006), fenpropathrin (Yang et al, 2013), and to adsorb heavy metal ions (Ozdemir et al, 2003). Several enzymes have been identified from the genus Ochrobactrum, including D-stereo specific amino acid amidase (Asano et al, 1989; Komeda et al, 2003), aminopeptidase (Bompard-Gilles et al, 2000), and glutathione S-transferase (Favaloro et al, 1998; Tamburro et al, 2004). They can also produce biosurfactant (Wasko and Bratt, 1991) and degrade nicotine (Yuan et al, 2005).
The optimization of growth conditions showed that $\mathrm{pH}$ 7 was the best for the growth of Ochrobactrum anthropi MP3 (Fig. 1) and $\mathrm{pH} 6$ was also good. The initial $\mathrm{pH}$ of the fermentation medium affects the morphology of an organism which influences EPS synthesis. However, there is only a relatively small effect of initial $\mathrm{pH}$ on the growth of Ochrobactrum anthropi MP3. Growth gradually increased with increasing initial $\mathrm{pH}$ up to 7 and then decreased. This is probably due to an influence of acidic or alkali $\mathrm{pH}$ on morphological characteristic of the organism.

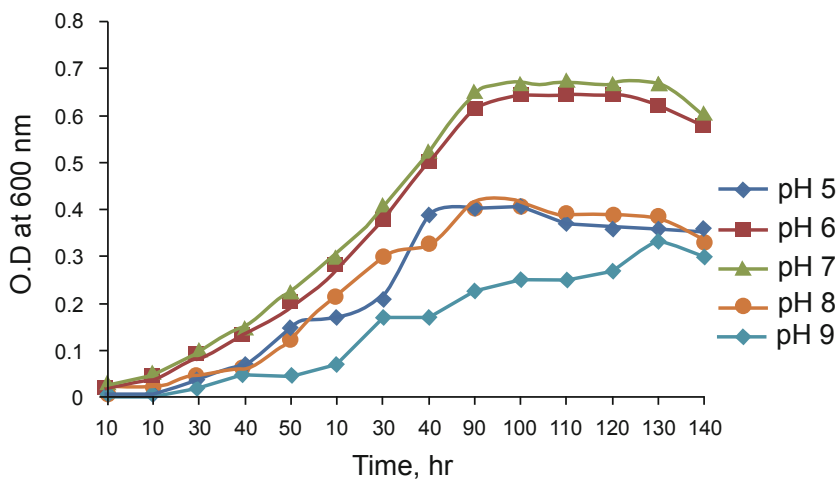

Fig. 1 Effect of $\mathrm{pH}$ on the growth of $O$. anthropi $M P 3$

The carbon source is mainly used as a cellular constituent, and for synthesis of new cells and production of polysaccharide as an energy source. Glucose served as the best carbon source (Fig. 2) in comparison with sucrose and fructose. A glucose concentration of $2 \%(\mathrm{w} / \mathrm{v})$ yielded the maximum growth of Ochrobactrum anthropi MP3 (Fig. 3). Thereafter the growth decreased with an increase of glucose concentration.

Depletion of nitrogen is regarded as a sign of exopolysaccharide formation. The nitrogen source affects the growth and metabolic activities of the organism. Sodium nitrate (Fig. 4) was found to be the most suitable nitrogen source of the three tested for bacterial growth. Thus sodium nitrate was used to study the effect of nitrogen concentration on bacterial growth. Fig. 5 shows that there was an increase in growth when supplemented with $1 \%(\mathrm{w} / \mathrm{v})$ sodium nitrate and a maximum at $2 \%(\mathrm{w} / \mathrm{v})$. The growth of Ochrobactrum anthropi MP3 reached its maximum at a diesel concentration of $2 \%(\mathrm{v} / \mathrm{v})$ when diesel was supplied as a hydrocarbon source (Fig. 6).

Under the above optimized conditions, the bacteria are grown aerobically for EPS production. The EPS which was secreted extracellularly was precipitated using cold ethanol.

Phetrong et al (2008) have found that precipitation of emulsifier from $A$. calcoaceticus sub sp. with ethanol is the most efficient method when compared with other precipitation methods. The precipitated EPS was dialyzed against distilled water for $24 \mathrm{hrs}$ and then lyophilized.

The yield of the lyophilized EPS was about $0.42 \mathrm{~g} / \mathrm{L}$ under the optimized growth conditions. 


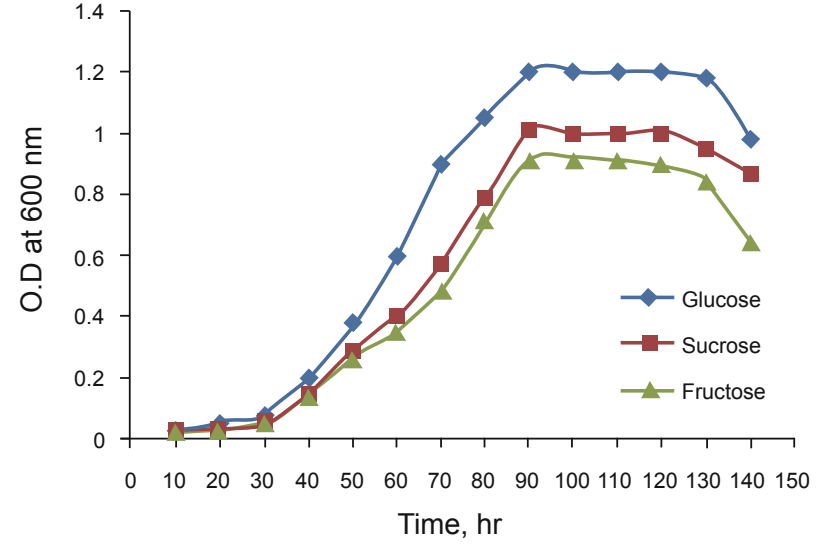

Fig. 2 Effect of some different carbon sources on the growth of $O$. anthropi MP3

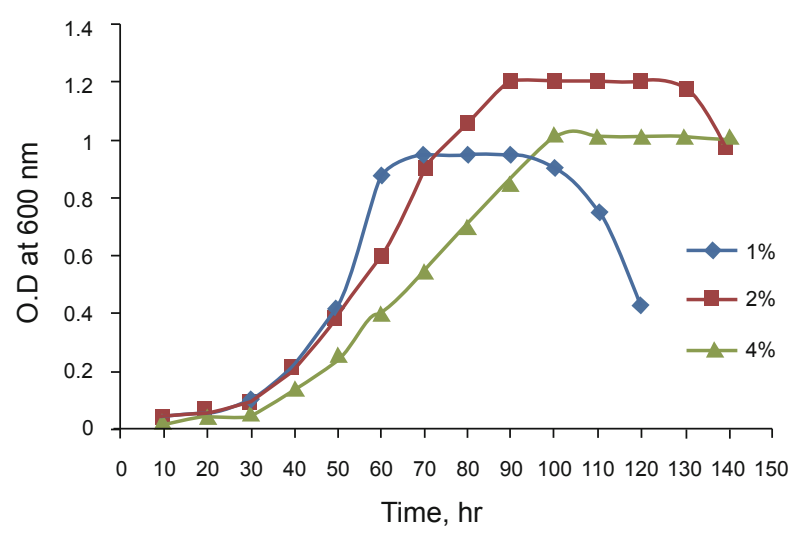

Fig. 3 Effect of glucose concentration on the growth of $O$. anthropi $M P 3$

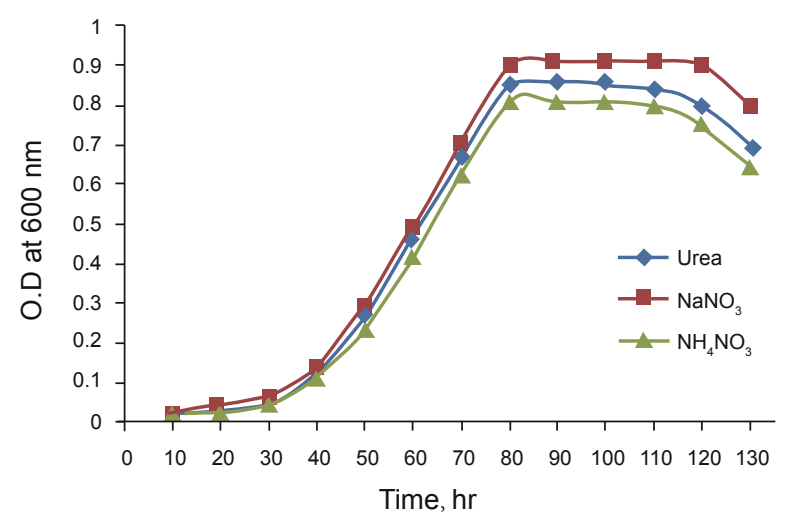

Fig. 4 Effect of different nitrogen sources on the growth of $O$. anthropi $M P 3$

The biochemical characterization of the EPS revealed that the total carbohydrate content was about $71.1 \%$, and the protein content was $19.7 \%$ which shows the glycoprotein nature of the EPS.

The ability of the EPS to form stable emulsions through emulsification activity test revealed that the emulsification activity of EPS was maximum for the diesel and minimum for the sunflower oil, and the emulsification activity of the EPS decreased in the order of diesel $>$ petrol $>$ kerosene $>$ sunflower oil (Table 2).

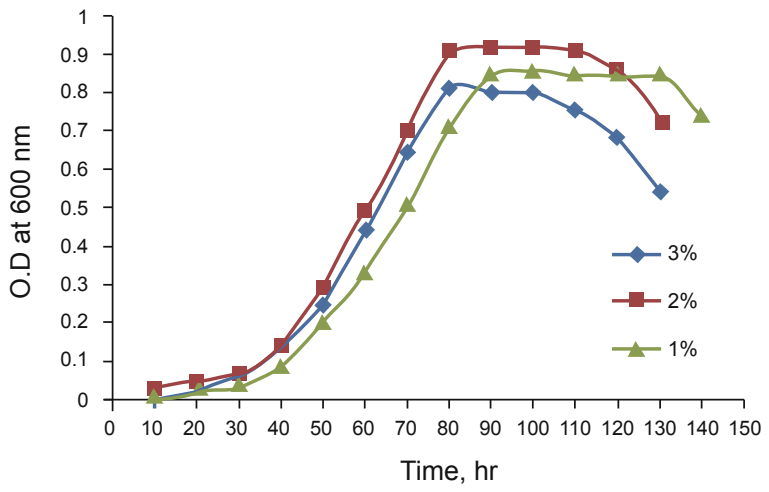

Fig. 5 Effect of sodium nitrate concentration on the growth of $O$. anthropi MP3

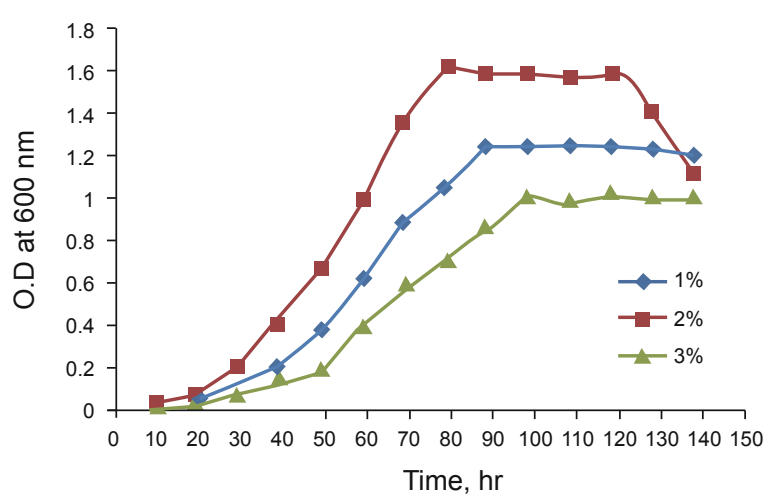

Fig. 6 Effect of diesel concentration on the growth of O. anthropi MP3

Table 2 Emulsification activity of EPS on different oils

\begin{tabular}{cc}
\hline Oil source & Emulsification activity, \% \\
\hline Diesel & $60 \pm 1$ \\
Petrol & $54 \pm 0.5$ \\
Kerosene & $50 \pm 0.5$ \\
Sunflower oil & $43 \pm 2$ \\
\hline
\end{tabular}

The cell surface hydrophobicity of the bacteria for hydrocarbon was about $57 \%$ by the BATH method.

Fig. 7 shows the FT-IR spectrum of the major functional groups and chemical compounds present in the EPS produced by $O$. anthropi $M P 3$. The peak at $3,401 \mathrm{~cm}^{-1}$ indicated the presence of hydroxyl groups $(-\mathrm{OH})$, and $\mathrm{C}-\mathrm{H}$ stretching was observed at $2,926 \mathrm{~cm}^{-1}$. The peak between $2,800 \mathrm{~cm}^{-1}$ and $3,000 \mathrm{~cm}^{-1}$ indicated $\mathrm{C}-\mathrm{H}$ aliphatic stretching. The peak at $1,169 \mathrm{~cm}^{-1}$ showed the presence of $-\mathrm{OH}$ groups. The absorption peak at about $1,050 \mathrm{~cm}^{-1}$ showed the presence of polysaccharide- or polysaccharide-like substance. The absorption peak at around $1,264 \mathrm{~cm}^{-1}$ could be attributed to the presence of sulphate group such as $\mathrm{S}-\mathrm{O}$. Ester compounds were observed at $1,738 \mathrm{~cm}^{-1}$. The peak at $1,313 \mathrm{~cm}^{-1}$ indicated the $\mathrm{C}-\mathrm{O}-\mathrm{C}$ aryl alkyl asymmetric group. Hydrogen bending on an aromatic ring could be observed at $800 \mathrm{~cm}^{-1}$. 


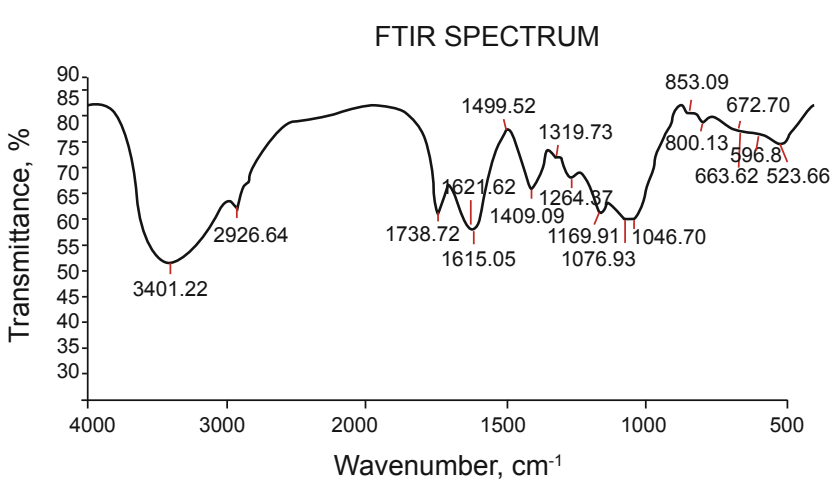

Fig. 7 FT-IR result of EPS produced by $O$. anthropi $M P 3$

C-O-S stretching was observed at $651 \mathrm{~cm}^{-1}$ and stretch of alkyl derivatives observed between $570 \mathrm{~cm}^{-1}$ and $590 \mathrm{~cm}^{-1}$.

The ${ }^{1} \mathrm{H}$ spectra NMR of EPS (Fig. 8) revealed the number of peaks (signals) corresponding to different sugar moieties, sulphated sugar etc. The chemical shift $\delta$ value between 1.1$1.2 \mathrm{ppm}$ showed methyl group $\left(-\mathrm{CH}_{3}\right)$ and the chemical shift $\delta$ value at $2.13 \mathrm{ppm}$ showed the presence of sulphate group. The sharpness of the signals at $\delta$ value of $3.6-3.8 \mathrm{ppm}$ indicated that those soluble compounds were probably not complexed to metal ions, but probably the glycosidic linkage of pentose/hexose sugars (Lima et al, 1995). The chemical shift $\delta$ value at 4.8-4.9 showed the alkene group possibly anomeric carbon of sugar moieties. Chemical shift $\delta$ value at $5.3 \mathrm{ppm}$ indicated the anomeric proton of $\beta(1 \rightarrow 4)$ linkage between D-glucose and D-glucose units. The $\delta$ value at 5.15 ppm showed the linkage $\beta(1 \rightarrow 4)$ between D-glucose and D-fructose.

Gas chromatography (GC) analysis showed significant peak reduction in test samples after one week compared to the control, suggesting degradation of all hydrocarbons (data not shown). It was found that about $53 \%$ of the oil was degraded by Ochrobactrum anthropi MP3 after one week. There is a

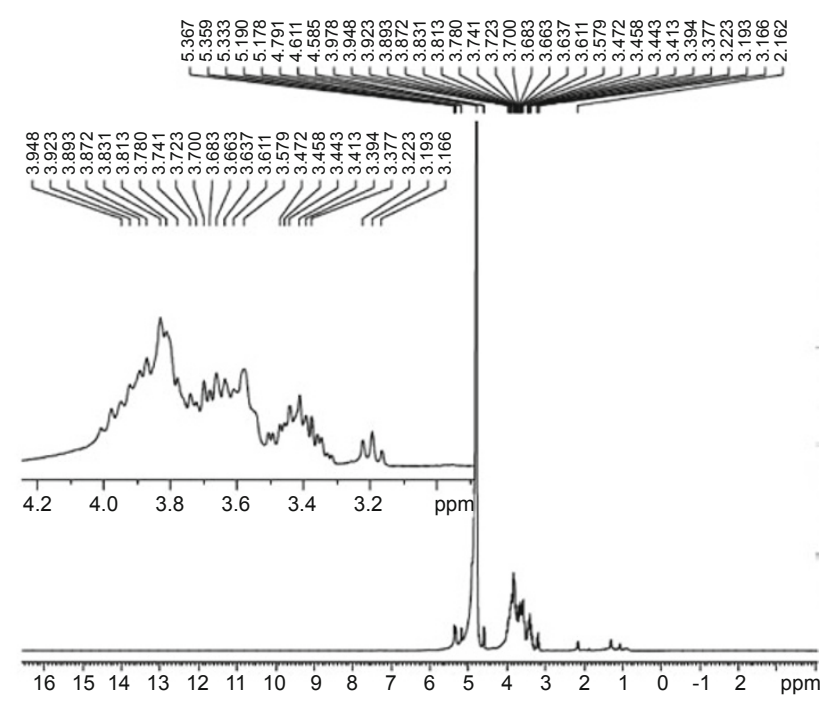

Fig. $8{ }^{1} \mathrm{H}$ NMR result of EPS produced by O. anthropi MP 3 possibility to increase the level of degradation by increasing the number of degradation days. Mandri and Lin (2007) reported that $90 \%$ of oil was degraded by $P$. aeruginosa after 4 weeks, showing the efficiency of the microorganism to utilize oil as the sole source of carbon and energy. Hydrocarbon does not have any toxic effect on the growth of the microorganisms. This may be due to the ability of the organisms to produce EPS, which may shield them from the toxic effects of the hydrocarbons.

\section{Conclusion}

The Ochrobactrum anthropi MP3 isolated from the PRW proved to be an efficient degrader of diesel oil. EPS produced by the bacteria displayed good emulsification activity on different oils. The study also revealed that the EPS produced by $O$. anthropi MP3 enhanced the uptake of oil as a sole carbon source and degraded the hydrocarbons present in the oil. Thus the present study shows the potential application of Ochrobactrum anthropi MP3 in EPS production and diesel oil degradation.

\section{Acknowledgements}

The authors are thankful to the Department of Science and Technology, India for financial support under fast track scheme for young scientist (SR/FT/LS-19/2012) and to Prof. Sethuraman, Vice -Chancellor, Shanmuga Arts, Science Technology and CeNTAB (SASTRA) for giving us a great opportunity to carry out the project.

\section{References}

Alvarez P J J and Vogel T M . Substrate interactions of benzene, toluene, and para-xylene during microbial degradation by pure cultures and mixed culture aquifer slurries. Applied Environmental Microbiology. 1991. 57: 2981-2985

Asano Y, Mori T, Hanamoto S, et al. A new D-stereo specific amino acid amidase from Ochrobactrum anthropi. Biochemical and Biophysical Research Communication. 1989. 162: 470-474

Bach H, Berdichevsky Y and Gutnick D. An exocellular protein from the oil-degrading microbe Acinetobacter venetianus RAG-1 enhances the emulsifying activity of the polymeric bioemulsifier emulsan. Applied Environmental Microbiology. 2003. 69: 2608-2615

Banat I M, Makkar R S and Cameorta S S. Potential commercial applications of microbial surfactants. Applied Microbial Biotechnology. 2000. 53: 495-508

Batista R M, Rufino R D, Luna J M, et al. Effect of medium components on the production of a biosurfactant from Candida tropicalis, applied to the removal of hydrophobic contaminants in Soil. Water Environment Research. 2010. 82: 1-8

Bompard-Gilles C, Remaut H, Villeret V, et al. Crystal structure of a D-amino peptidase from Ochrobactrum anthropi, a new member of the 'penicillin-recognizing enzyme' family. Structure. 2000. 8: 971980

Bongkeuu S, Palleroni N J and Haggblom M M. Isolation and characterization of diverse halobenzoate degrading denitrifying bacteria from soils and sediments. Applied and Environmental Microbiology. 2000. 66: 3446-3453

Cooper D J and Goldenberg B G. Surface active agents from two Bacillus species. Applied Environmental Microbiology. 1987. 54: 224-229 
Dasgupta D, Ghosh R and Sengupta T K. Biofilm-mediated enhanced crude oil degradation by newly isolated Pseudomonas species. ISRN Biotechnology. Hindawi Publishing Corporation.

El-Sayed W S, Ibrahim M K, Abu-Shady M, et al. Isolation and identification of a novel strain of the genus Ochrobactrum with phenol-degrading activity. Journal of Bioscience and Bioengineering. 2003. 96: 310-312

Favaloro B, Melino S, Petruzzelli R, et al. Purification and characterization of a novel glutathione transferase from Ochrobactrum anthropi. FEMS Microbiology Letters. 1998. 160: 8186

Ghosal D, Chakraborty J, Khara P, et al. Degradation of phenanthrene via meta-cleavage of 2-hydroxy-1-naphthoic acid by Ochrobactrum sp. strain PWTJD. FEMS Microbiology Letters. 2010. 313: 103-110

Goris J, De Vos P, Caballero-Mellado J, et al. Classification of the biphenyl- and polychlorinated biphenyl-degrading strain LB400T and relatives as Burkholderia xenovorans sp. nov. International Journal of Systematic and Evolutionary Microbiology. 2004. 54: 1677

Holliger C, Gaspard S, Glod G, et al. Contaminated environments in the subsurface and bioremediation: organic contaminants. FEMS Microbiology Reviews. 1997. 20: 517-523

Komeda H, Ishikawa N and Asano Y. Enhancement of the thermo stability and catalytic activity of D-stereo specific amino-acid amidase from Ochrobactrum anthropi SV3 by directed evolution. Journal of Molecular Catalysis B: Enzymatic. 2003. 21: 283-290

Kvenvolden K A and Cooper C.K. Natural seepage of crude oil into the marine environment. Geo-Marine Letters. 2003. 23: 140-146

Laura D, De Socio, Frassanito R, et al. Effects of atrazine on Ochrobactrum anthropi membrane fatty acids. Applied and Environmental Microbiology. 1996. 62: 2644-2046

Lechner U, Baumbach R, Becker D, et al. Degradation of 4-chloro2-methyl phenol by an activated sludge isolate and its taxonomic description. Biodegradation. 1995. 6: 83-92

Lima E C O, Neto J M M, Fujiwara F Y, et al. Aluminum polyphosphate thermoreversible gels: a study by $31 \mathrm{P}$ and $27 \mathrm{Al}$ NMR spectroscopy. Journal of Colloid and Interface Science. 1995. 176: 388-396

Lowry O H, Rosebrough N J, Farr A L, et al. Protein measurement with the folin phenol reagent. Journal of Biological Chemistry. 1951. 193: $265-275$

Luna J M, Rufino R D, Albuquerque C D C, et al. Economic optimized medium for tensio-active agent production by Candida sphaerica UCP0995 and application in the removal of hydrophobic contaminant from sand. International Journal of Molecular Sciences. 2011. 12: 2463-2476

Mack D, Fischer W, Krokotsch A, et al. The intercellular adhesin involved in biofilm accumulation of Staphylococcus epidermidis is a linear $\beta$-1,6-linked glucosaminoglycan: purification and structural analysis. Journal of Bacteriology. 1996. 178: 175-183

Mandri T and Lin J. Isolation and characterization of engine oil degrading indigenous microorganisms in Kwazulu-Natal, South Africa. African Journal of Biotechnology. 2007. 6(1): 023-027

Margesin R and Schinner F. Bioremediation (natural attenuation and biostimulation) of diesel-oil-polluted soil in an Alpine Glacier skiing area. Applied and Environmental Microbiology. 2001. 67: $3127-$ 3133

Mariano A P, Bonotto D M, De Angelis D F, et al. Biodegradability of commercial and weathered diesel oils. Brazilian Journal of Microbiology. 2008. 39: 133-142

Michaud L, Lo Giudice A, Saitta M, et al. The biodegradation efficiency on diesel oil by two psychrotrophic antarctic marine bacteria during a two-month-long experiment. Marine Pollution Bulletin. 2004. 49: 405-409

Ozdemir G, Ozturk T, Ceyhan N, et al. Heavy metal biosorption by biomass of Ochrobactrum anthropi producing exopolysaccharide in activated sludge. Bioresource Technology. 2003. 90: 71-74

Phetrong K, H-Kittikun A and Maneerat S. Production and characterization of bioemulsifier from a marine bacterium, Acinetobacter calcoaceticus subsp. anitratus SM7. The Songklanakarin Journal of Science and Technology. 2008. 30(3): 297-305

Rosenberg M, Gutnick D and Rosenberg E. Adherence to bacteria to hydrocarbons: a simple method for measuring cell-surface hydrophobicity. FEMS Microbiology Letters. 1980. 9: 29-33

Spiro R G. Analysis of sugar found in glycoproteins. Methods in Enzymology. 1996. 8: 7-9

Sultan S and Hasnain S. Characterization of an Ochrobactrum intermedium strain STCr-5 manifesting high level Cr (VI) resistance and reduction potential. Enzyme and Microbial Technology. 2006. 39: $883-888$

Sutherland I. W. Biotechnology of Exopolysaccharides. Cambridge: Cambridge University Press. 1990

Tamburro A, Robuffo I, Heipieper H J, et al. Expression of glutathione S-transferase and peptide methionine sulphoxide reductase in Ochrobactrum anthropi is correlated to the production of reactive oxygen species caused by aromatic substrates. FEMS Microbiology Letters. 2004. 241: 151-156

Wasko M P and Bratt R P. Properties of a biosurfactant produced by the fuel contaminant Ochrobactrum anthropi. International Biodeterioration and Biodegradation. 1991. 27: 265-273

Yang N, Zhang R, Xiang Z, et al. Study the optimal condition of fenpropathrin degradation by Ochrobactrum anthropi based on bacteria microscopic image detection method. Advance Journal of Food Science and Technology. 2013. 5(6): 688-694

Yuan Y J, Lu Z X, Wu N, et al. Isolation and preliminary characterization of a novel nicotine-degrading bacterium, Ochrobactrum intermedium DN2. International Biodeterioration and Biodegradation. 2005. 56: 45-50

(Edited by Zhu Xiuqin) 